\title{
Regional Market Characteristics and Integrating Mechanism of Environmental Pollution Third-Party Governance Service in China
}

\author{
Liping Cao*, Fengqi Zhou
}

Institute of Ecology and Sustainable Development, Shanghai Academy of Social Sciences, Shanghai, China

Email: *clp-ww@163.com

How to cite this paper: Cao, L. P., \& Zhou, F. Q. (2020). Regional Market Characteristics and Integrating Mechanism of Environmental Pollution Third-Party Governance Service in China. Journal of Service Science and Management, 13, 785-808. https://doi.org/10.4236/jssm.2020.136049

Received: October 14, 2020

Accepted: November 16, 2020

Published: November 19, 2020

Copyright $\odot 2020$ by author(s) and Scientific Research Publishing Inc. This work is licensed under the Creative Commons Attribution International License (CC BY 4.0).

http://creativecommons.org/licenses/by/4.0/

\begin{abstract}
The market integrating mechanism of environmental pollution third-party governance service in the Yangtze River Delta of China will promote the integration level of the whole regional ecological environment governance. In this paper, based on analysis of environmental pollution third-party governance situations, and market characteristics of integration in Yangtze River Delta, firstly, the market integrating level of environmental pollution third-party governance service in this region would be scientifically measured by using market integration indicators extracted from integrating evaluation index system of Yangtze River Delta. Secondly, three constructing factors which aspect regional market behaviors of environmental pollution third-party governance service should be found after analyzing the root causes, including constructing recognition mechanism for local pollution emission compliance standard and environmental service industry standard in Yangtze River Delta, constructing corporation mechanism for multiple subjects of environmental pollution third-party governance service, and constructing unite regionally environmental regulatory enforcement procedures in this region. Thirdly, according to the Structure-Behavior-Performance (SCP) analysis paradigm of industrial economics, the market integrating construction paths of environmental pollution third-party governance in the Yangtze River Delta are proposed. Finally, the paper discusses the strategies of constructing market integrating mechanism for environmental pollution third-party governance service in Yangtze River Delta.
\end{abstract}

\section{Keywords}

Yangtze River Delta, Environmental Pollution, Third-Party Governance Service, Market Characteristics, Integration Mechanism 


\section{Introduction}

The development of regional integration in Yangtze River Delta of China has become a national strategy, which is on par with the integration of the Beijing-Tianjin-Hebei urban agglomeration and the Guangdong-Hong Kong-Macao Greater Bay Area. Furthermore, constructing beautiful and green Yangtze River Delta is a high-quality development requirement in the field of ecological and environmental protection for Yangtze River Delta. According to the overall layout of "Five-in-One" proposed by China, regionally ecological and green integration should also be the meaning of realizing the integrated development of Yangtze River Delta. The regional integration of Yangtze River Delta promoted by economic globalization in the $21^{\text {st }}$ century is essentially an economic problem (Hu, 2019). Environmental problems are part of economic problems, so they are inseparable from environmental service industry that meets the needs of better ecological environment protection, and the accompanying environmental pollution third-party governance market (Huang et al., 2017). The academic circles think that the introduction of environmental third-party governance is to explore the relationship between different governance subjects. Among them, the core is the interdependence of resources and the essence is the interdependence of interests (Chen, 2017). Professionally environmental pollution third-party governance model is a tool of modern innovation of ecological and environmental governance in China, and market integration development of regionally environmental pollution third-party governance is able to enhance the integrating level of ecological and green modernization management in Yangtze River Delta, under the requirement of Yangtze River Delta integration Strategy (Sun \& Cheng, 2019). At present, researches on environmental pollution third-party governance mainly focus on connotation (Luo, 2014), characteristics (Liu, 2015), patterns (Zeng et al., 2018; Huang \& Ding, 2019), institutional logic (Zhou, 2017; Lu \& Lin, 2019), theoretical basis and mechanism of action (Dong et al., 2016), defining the legal responsibilities (Liu, 2018), and other basic problems, also including to identify key influencing elements of environmental pollution third-party governance, obstacles and difficulties (Xie, 2014; Li \& Mao, 2018) through foreign outstanding cases (Wan, 2017), relevant practices (Ren \& Wang, 2014). There are a few policy studies analyzing the mechanism of environmental pollution third-party governance about the integration of regionally environmental pollution governance (Song, 2014). The latest research in China proposes an optimal path for the socializing environmental pollution third-party governance mechanism from the legal perspective of environmental risk prevention and public participation (Zhang, 2020). However, there is little research on the integrating mechanism of regionally environmental pollution third-party market governance. As the important concentrated area for supply bodies of environmental pollution third-party governance service, there are many inconsistent regionally environmental pollution governance service standard problems and "market failure", such as local mo- 
nopolies in Yangtze River Delta, where local governments may have different regionally environmental governance requirements and the service supplies with different pollution governance level, and resulting in market segmentation of regionally environmental pollution third-party governance. Therefore, based on sorting out the status and market characteristics of environmental pollution third-party governance in Yangtze River Delta, this paper measures the influencing factors of the integrating level of environmental pollution third-party governance market, and then discusses the construction path and integrating strategy of environmental pollution third-party governance market in Yangtze River Delta.

Regional perspective will be a new perspective to study environmental pollution third-party governance market in Yangtze River Delta of China. The regionally environmental pollution third-party governance market integration referred in this article is means to making jointly regional cooperation agreements or market legal policies for regionally environmental service and standard ways among three provinces and one municipality's local government departments, including opening environment pollution third-party governance market, promoting mobility of high quality elements, such as talents, technology, capital of environment pollution third-party governance service, in order to eliminate regionally administrative barriers of service market and local protection, and gain the interests of the regionally environmental trade action.

\section{Data Sources and Methods}

\subsection{Data Source}

Firstly, market integration status and characteristics of environment pollution third-party governance in Yangtze River Delta are analyzed, by using the latest industrial development data of environmental pollution third-party governance, mainly come from national statistics of three provinces and one municipality (those are Jiangsu province, Zhejiang province, Anhui province, Shanghai municipality) in Yangtze River Delta, the fourth national environmental protection and related industry survey data (2011), the environmental protection industry boom report (2017-2018): A-share listed environmental protection enterprises \& the New Third Board environmental protection enterprise, the environmental protection industry boom report (2019) in the first \& second quarter: A-share listed environmental protection enterprises. Secondly, market integrating level of regionally environmental pollution third-party governance in Yangtze River Delta are measured, by using the data mainly comes from national statistics which are relevant statistical data of the three provinces and one municipality in Yangtze River Delta, including statistical yearbook of three provinces and one municipality (2018), the payment report of environmental protection industry (2017), the forecast report of environmental technology in 2018, etc. 


\subsection{Methods}

\subsubsection{Evaluation Method for Market Integrating Level of Environmental Pollution Third-Party Governance in Yangtze River Delta}

Market integrating level indicator used in this paper is extracted from integration evaluation index system in Yangtze River Delta built by Zhu Ping fang team (2017) in Shanghai academy of social sciences, and then fixing indicator to form market integration index system of environmental pollution governance third-party in Yangtze River Delta. There are four influence factors in the new index system which could scientifically measure market integration level of environmental pollution third-party governance in Yangtze River Delta, including talent, technology, finance, degree of industry isomorphism of environmental pollution third-party governance service market. Where, $S_{i j}$ is the industrial structure coefficient between regional markets, illustrating the structure similarity coefficient of Region $I$ and Region $J$, which are two comparative regions. $X_{i k}$ is the proportion of $K$ industry in region $I . S_{i j}$ varies between 0 and 1 . If the value of $S_{i j}$ is 0 , the industrial structure of the two comparative regions is completely different. If the value is 1 , the industrial structure between the two regions is identical. In other words, the greater the $S_{i j}$ value is, the greater the industrial isomorphism between the two comparative regions is. Conversely, it indicates that the degree of isomorphism is lower.

$$
S_{i j}=\sum_{k=1}^{n}\left(X_{i k} X_{j k}\right) / \sqrt{\sum_{k=1}^{n} X_{i k}^{2} \sum_{k=1}^{n} X_{j k}^{2}}
$$

\subsubsection{The Analysis Paradigm of Structure-Behavior-Performance (SCP)} SCP model provides an industry analysis framework that can not only deepen specific links but also have systematic logic system (Pei et al., 2018). The basic meaning of SCP framework is that the market structure determines the behavior of enterprises in the market, and the behavior of enterprises determines the economic performance of the market operation in various aspects. Therefore, the market structure of environmental governance in the Yangtze River Delta determines the behavior of environmental governance third-party enterprises and their stakeholders in the regional market, including the government, polluters, and investment and financing institutions, and ultimately determines the overall market performance of environmental governance third-party in Yangtze River Delta.

\section{The Integrated Status and Market Characteristics of Environmental Pollution Third-Party Governance in Yangtze River Delta}

\subsection{The Integrated Status of Environmental Pollution Third-Party Governance Market}

The Environmental protection industry in the Yangtze River Delta region has started earlier and has a good development foundation, which is an important 
cluster area of environmental pollution third-party governance services (Xue et al., 2016). According to the statistical data of the three provinces and one municipality in the Yangtze River Delta, the number of enterprise engaged in environmental and public facility management services and the scale of fixed asset investment in the Yangtze River Delta region in the past 10 years show an increasing trend. In 2017, the number of enterprises reached 30,819, with 408,600 employees, and the scale of fixed asset investment reached 1348 billion yuan (RMB) (Figure 1).

Although the overall scale of the environmental service industry in Yangtze River Delta is large and its economic benefits are better than the national average, its market performance is still lower than that in the Pearl River Delta, Bohai Rim, and other key regions. At the same time, based on survey data of the fourth national environmental protection and related industry (2011), and using SCP model of industry economics, the niche industry of environmental pollution third-party governance service with higher concentration currently are including: environmental consulting services, its market concentration ratio $\left(\mathrm{CR}_{4}\right)$ value is above 25\%; environmental engineering construction service industry, its market concentration ratio $\left(\mathrm{CR}_{4}\right)$ value is about $15 \%$; service industry of pollution control and environmental protection facility operation, its concentration ratio $\left(\mathrm{CR}_{4}\right)$ value is above $10 \%$ (Figure 2 ) from the perspective of industry market segment for environment pollution third-party governance service in Yangtze River Delta. However, the income from pollution control and environmental protection facility operation is the highest, followed by the income from environmental engineering construction, and the income from environmental consulting is the third from the perspective of operating income.

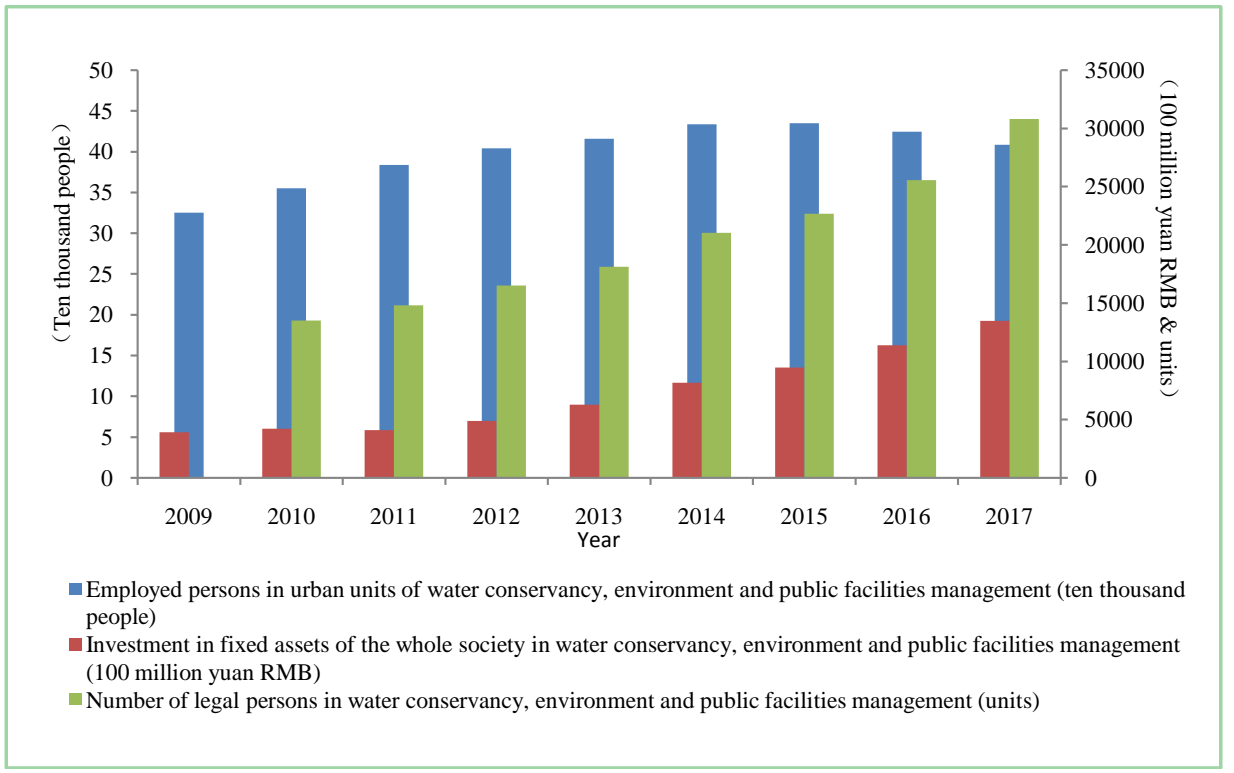

Figure 1. The overall scale of the water conservancy, environment, and public facilities management industry of Yangtze River Delta in the past 10 years. (data source: http://data.stats.gov.cn/). 


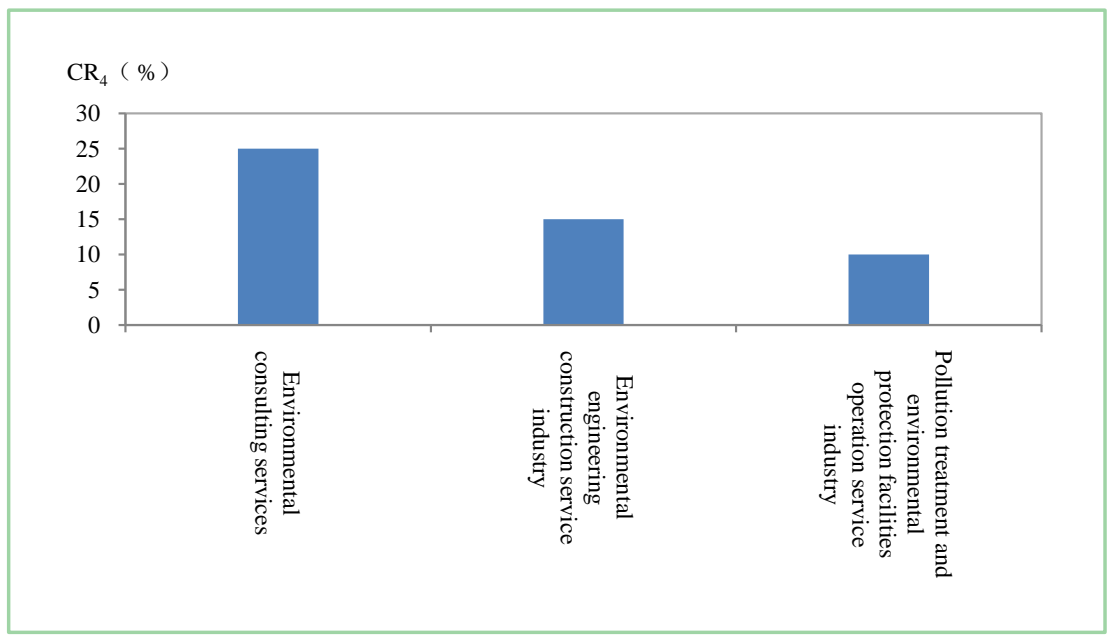

Figure 2. The top three $\mathrm{CR}_{4}$ in the concentration ratio of environmental service industries in Yangtze River Delta. (Data source: The fourth National Survey of Environmental Protection and Related Industries (2011)).

At present, China's environmental service industry has become a systematic service industry that provides overall solutions for environmental protection and pollution prevention and control based on the needs of a better ecological environment requirement. The environmental pollution third-party governance industry of in the Yangtze River Delta mainly involves air, water and solid waste pollution prevention and governance (Figure 3). Among them, the country's air pollution governance enterprises mainly concentrated in the Yangtze River Delta; Third-party water pollution governance enterprises are concentrated in the urban agglomeration along the upstream source of the Yangtze River and extend to the cities of the Yangtze River Delta. In the field of solid waste prevention and governance, the environmental pollution third-party governance enterprises in the Yangtze River Delta are mainly concentrated in Jiangsu province (Figure 4).

\subsection{The Characteristics of the Integrated Construction}

However, it can be found that the development of environmental service industry in each region is not only different in administrative division, but also different in different environmental fields and different market segments by analyzing the market of environmental service industry in three provinces and one municipality in Yangtze River Delta.

First of all, from the aspect of number of listed environmental protection service enterprises in Yangtze River Delta region, environmental protection industry boom report (2017 \& 2018) data show: the proportion of the listed companies engaged environmental pollution third-party governance in Yangtze River Delta region is account for $34 \%$ of the country, those are mainly distributed in Zhejiang province and Jiangsu province, but the number of listed environmental protection enterprises have declined from last year (Figure 5). From the aspect of 10 years' statistics of three provinces and one municipality in Yangtze River 


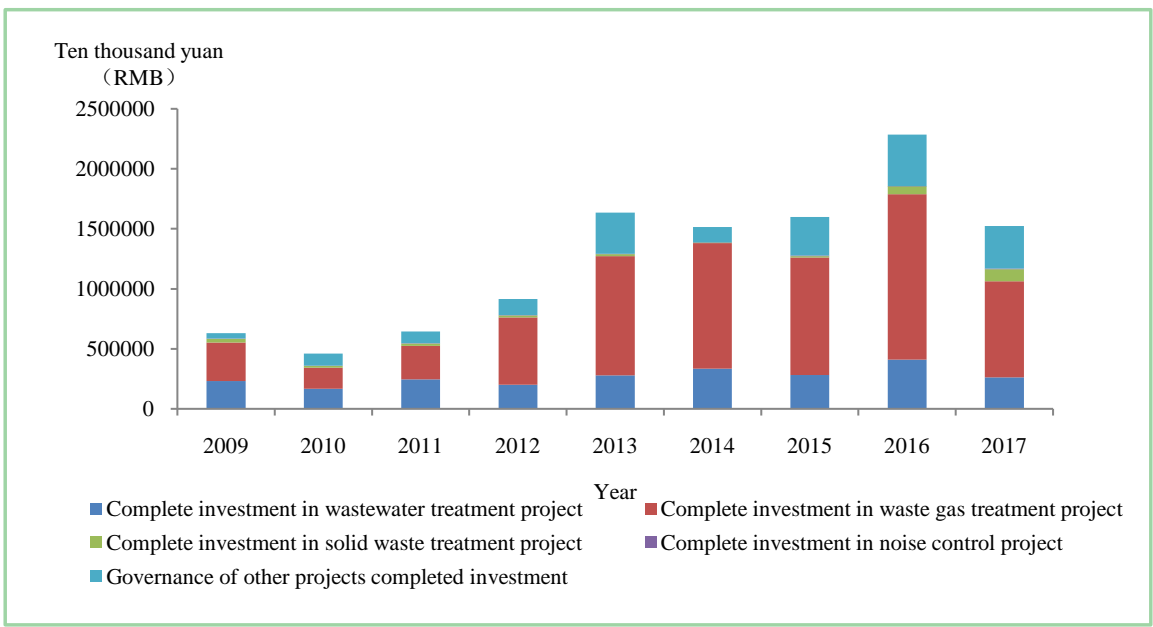

Figure 3. Investment scale of industrial pollution control projects in the environmental sector of Yangtze River Delta in the past 10 years. (Data source: http://data.stats.gov.cn/).

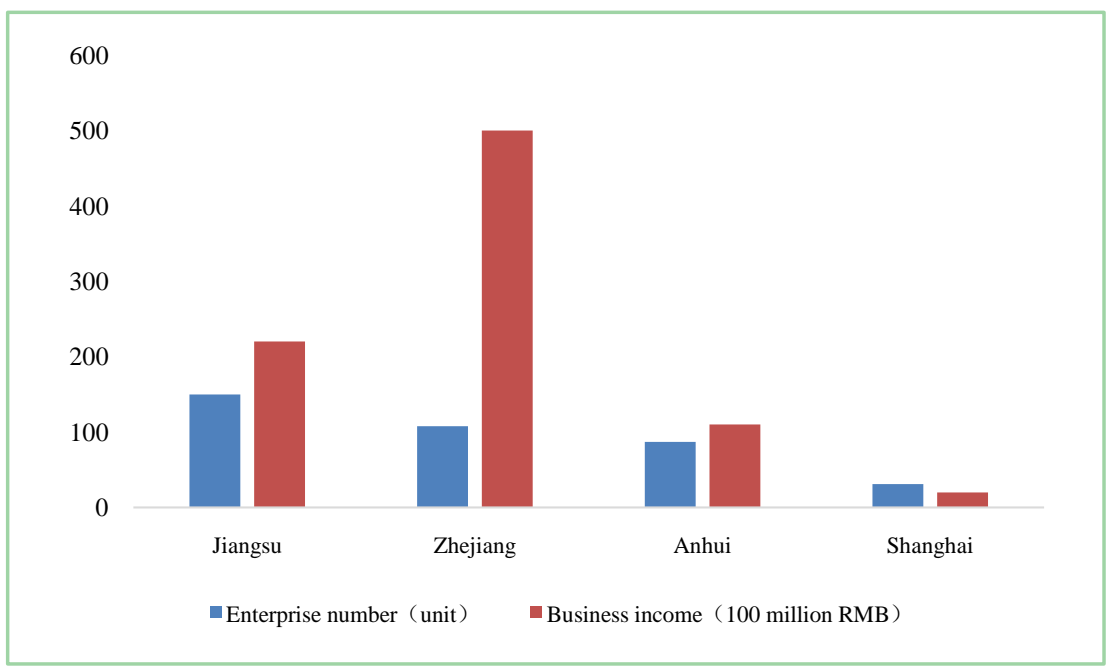

Figure 4. Enterprise number and business income of solid waste prevention and governance service in Yangtze River Delta in 2018. (Data source: 2019 China Environmental Protection Industry Analysis Report).

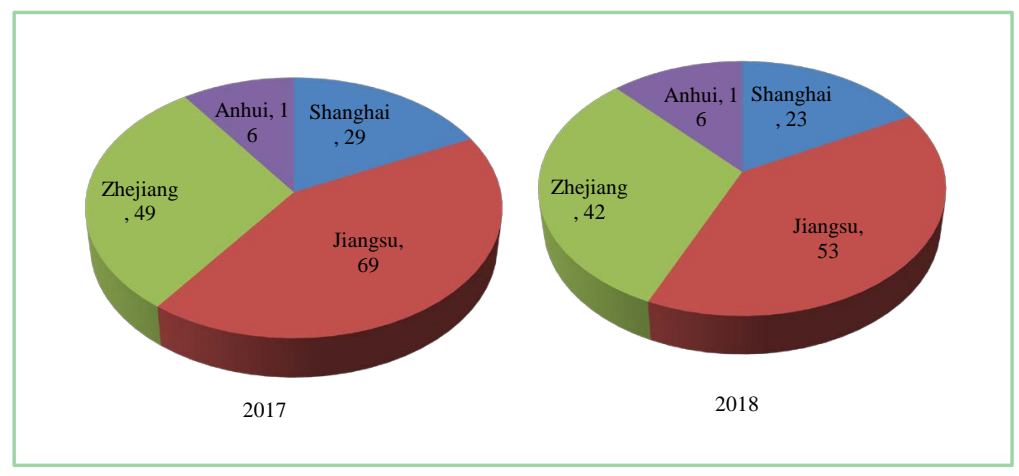

Figure 5. The number and spatial distribution of listed environmental protection companies in Yangtze River Delta in 2017 Vs 2018. (Data source: 2017-2018 Environmental Protection Industry Boom Report: A-share listed environmental protection enterprises, New Third Board environmental protection enterprises). 
Delta recently, the number of environmental service enterprise and the scale of investment in fixed assets in Jiangsu province, Zhejiang province and Anhui province are far more than Shanghai municipality (Figure 6 and Figure 7), but since China put forward the concept of ecological civilization construction in 2013, a large number of technical talents for environmental governance service have poured into the open market Shanghai, forming a talent regional agglomeration area in the Yangtze River Delta, therefore staff number per capita of the environmental services entrepreneur in Shanghai municipality is far more than in Jiangsu province, Zhejiang province, Anhui province (Figure 8) since 2013, and the development level environment service industry in Shanghai municipality is higher than other provinces Yangtze River Delta.

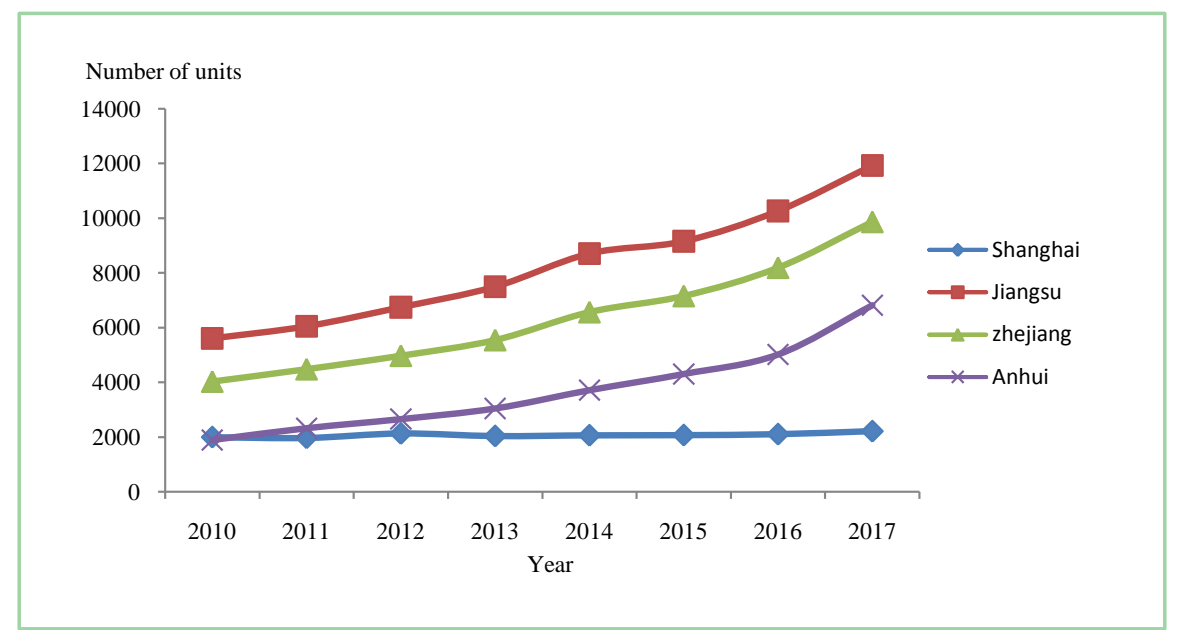

Figure 6. Number of water conservancy, environment, and public facilities management enterprises in three provinces and one municipality in Yangtze River Delta in the past 10 years. (Data source: National data http://data.stats.gov.cn/).

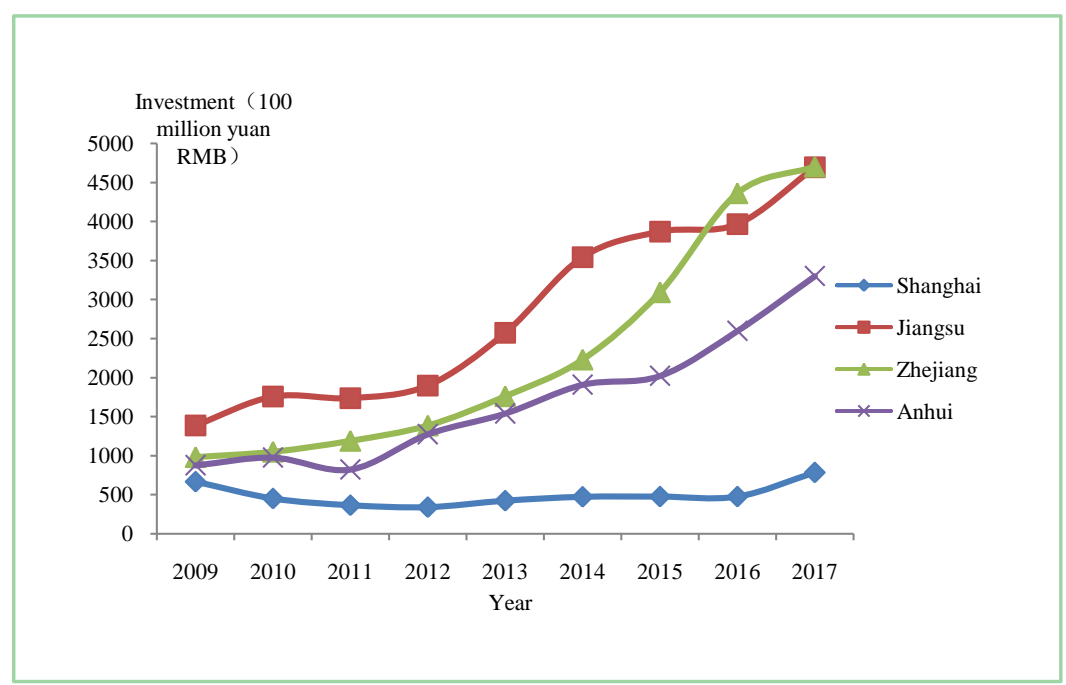

Figure 7. The scale of fixed asset investment in water conservancy, environment, and public facilities management in the three provinces and one municipality of Yangtze River Delta in the past 10 years. (Data source: National data http://data.stats.gov.cn/). 


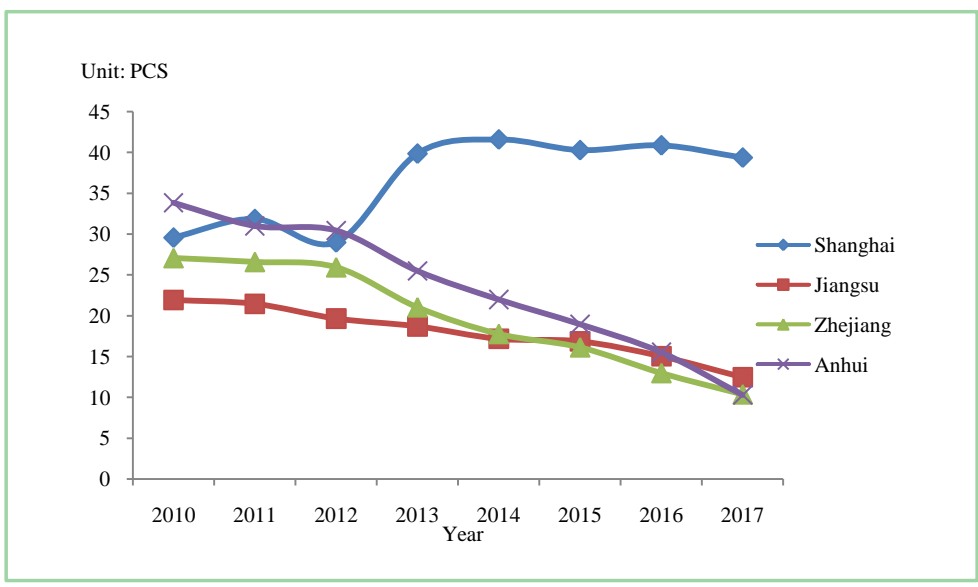

Figure 8. Number of employed persons in water conservancy, environment, and public facilities management in three provinces and one municipality of Yangtze River Delta in the past 10 years. (Data source: National data http://data.stats.gov.cn/).

Secondly, from aspect of market scale in three provinces and one municipality of Yangtze River Delta, 2019 (Table 1), A-shares listed on the environmental protection enterprise in the field of environmental governance services mainly include five segments which are prevention and governance of atmospheric pollution, water pollution governance, solid waste treatment and resource recovery, environment monitoring and detection, environmental restoration. In the first half of 2019, listed companies engaged in air pollution prevention and governance services were mainly concentrated in Jiangsu province and Zhejiang province, with main business revenue reaching 5.207 billion yuan (RMB). Listed enterprises engaged in water pollution prevention and governance services are evenly distributed in three provinces and one municipality, with main business income reaching 6.01 billion yuan (RMB). Listed enterprises engaged in solid waste treatment and resource recovery services are mainly distributed in Jiangsu province and Zhejiang province, also in Shanghai municipality and Anhui province, with the main business income reaching 14.33 billion yuan (RMB). Listed companies engaged in environmental monitoring and monitoring and environmental restoration services are mainly distributed in Jiangsu province and Zhejiang province, with the main business income of these two environmental governance services reaching 2.311 billion yuan (RMB) (Figure 9). In terms of overall scale, environmental protection enterprises listed in A-shares are mainly concentrated in Zhejiang province and Jiangsu province. Thirdly, from the aspect of main business income of the environmental protection companies in the market segment listed in the A-shares of the three provinces and one municipality of Yangtze River Delta in 2019 (Figure 10), Snice the "the strictest" garbage classification measures have been implemented in Shanghai municipality from 2019, which is called "Household Waste Management Regulations in Shanghai", the household waste third-party governance industry in the Yangtze River Delta has also developed. Solid waste governance and resource 
recovery services in environmental protection enterprises listed in A-shares in the first half of 2019 have become the main profit points of regionally environmental pollution third-party governance industry. And water pollution prevention and governance services are still an important part of environmental pollution third-party governance in three provinces and one municipality of Yangtze River Delta. Meanwhile, due to the complexity of the input of air pollution sources, even if there is an overall improvement of air environment governance in Yangtze River Delta, and the main pollutants show a downward trend, but the demand for air pollution prevention and governance services is still mainly concentrated in Jiangsu province and Zhejiang province. Furthermore, Zhejiang province's environmental monitoring and detection services have become the industry leader in environmental pollution third-party governance in Yangtze River Delta, which leads in the application of "Internet +" technology.

Table 1. Number of A-share listed environmental protection companies in three provinces and one municipality of Yangtze River Delta in the first half of 2019.

\begin{tabular}{ccccc}
$\begin{array}{c}\text { region environmental } \\
\text { governance field }\end{array}$ & $\begin{array}{c}\text { Shanghai } \\
\text { province }\end{array}$ & $\begin{array}{c}\text { Jiangsu } \\
\text { province }\end{array}$ & $\begin{array}{c}\text { Zhejiang } \\
\text { province }\end{array}$ & $\begin{array}{c}\text { Anhui } \\
\text { province }\end{array}$ \\
\hline $\begin{array}{c}\text { Air pollution prevention } \\
\text { Water pollution prevention }\end{array}$ & 0 & 5 & 4 & 0 \\
Solid waste treatment and recycling & 1 & 6 & 2 & 3 \\
Environmental monitoring and testing & 0 & 3 & 4 & 1 \\
Environmental restoration & 0 & 1 & 1 & 0 \\
total & 6 & 16 & 13 & 4 \\
\hline
\end{tabular}

(Data source: Boom report of environmental protection industry in the first and second quarters of 2019: A-share listed environmental protection companies).

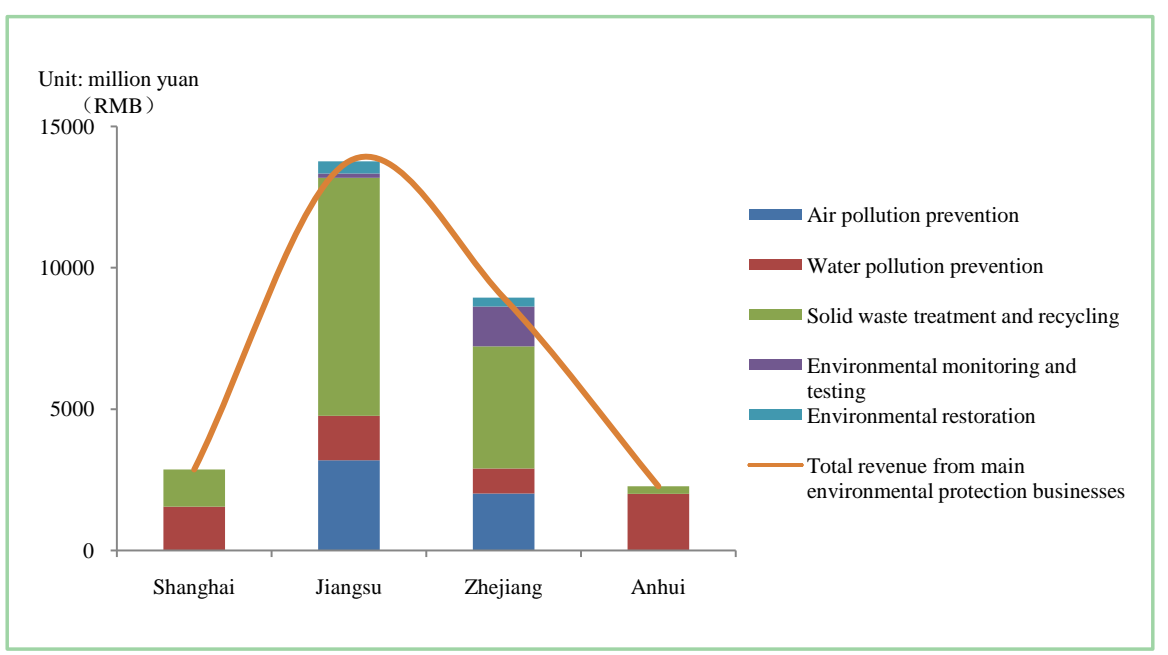

Figure 9. Comparison of market size of environmental service areas in three provinces and one municipality in Yangtze River Delta. (Data source: Boom report on environmental protection industry in the first and second quarters of 2019: A-share listed environmental protection companies). 


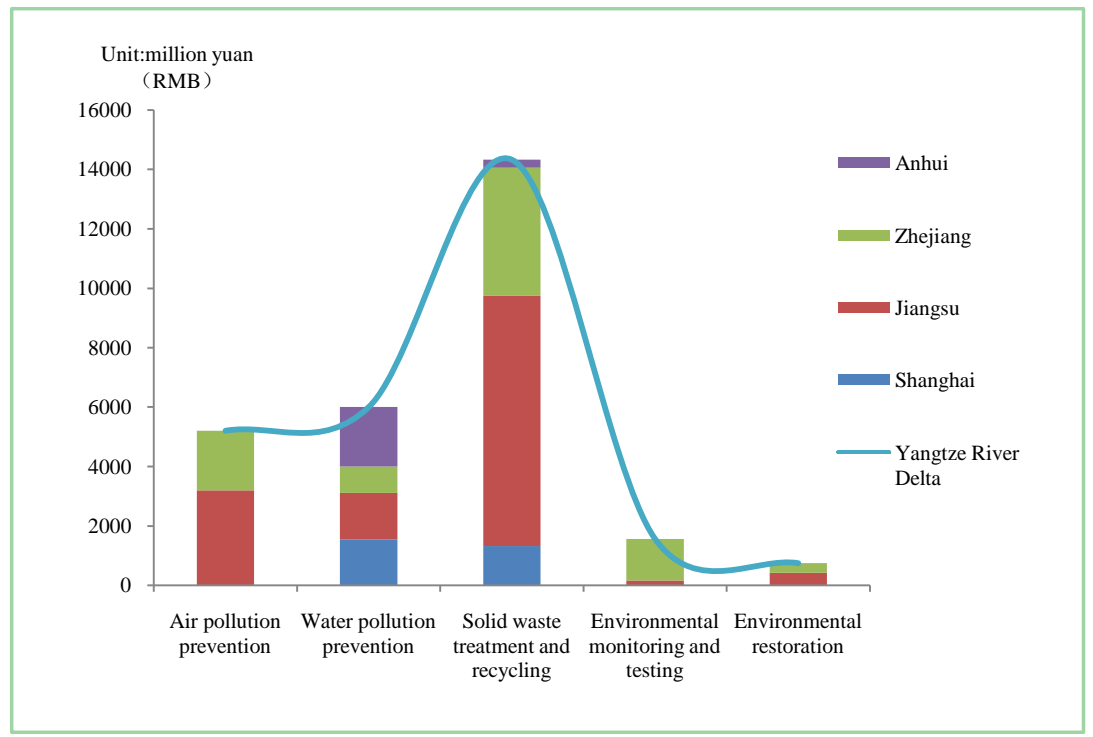

Figure 10. Comparison of main business income of environmental service segments in three provinces and one municipality in Yangtze River Delta. (Data source: The first quarter of 2019 and the second quarter of the environmental protection industry boom report: A-share listed environmental protection companies).

In general, the development of environmental pollution third-party governance industry segments and market segments in the three provinces and one municipality of the Yangtze River Delta is characterized by spatial imbalance, and the environmental governance service markets in Shanghai municipality and Anhui province and Jiangsu province and Zhejiang province are isomorphic in terms of the subdivided industrial structure. With the diversified demands of enterprises and society for ecological and environmental governance services, the environmental pollution third-party governance industry in Yangtze River Delta needs to carry out supply-side reforms such as strengthening weak points, reducing costs, and increasing efficiency, to promote the construction of regional market integration system.

\section{Measurement of Factors Influencing Integrating Environmental Pollution Third-Party Governance Market in Yangtze River Delta}

The market integration of environmental pollution third-party governance in Yangtze River Delta is a part of the integration of the Yangtze River Delta market. However, environmental pollution third-party governance model can more satisfy people's demand for ecological environment quality improvement and improving enterprise environmental management level for the local government, whose market integration construction is different from other general commodities and services market, that needs more coordination and cooperation between local governments, and formulating corresponding market integration guarantee across the administrative regions. Therefore, it is necessary to use a scientific index system to measure and analyze the factors influencing the inte- 
gration of environmental pollution third-party governance market in Yangtze River Delta to explore the important paths of its integration construction.

\subsection{Measurement of Integrating Factors of Environmental Pollution Third-Party Governance Market in Yangtze River Delta}

This article uses integration evaluation index system of Yangtze River Delta established by Zhu Pingfang research team of Shanghai Academy of Social Sciences to measure market integrating level indicators (Li \& Zhu, 2017), and revises the indicators to form a new indicator system (Table 2). In order to scientifically measure the market integrating level environmental pollution third-party governance service in Yangtze River Delta, there are four aspects of market integration impact factors in integrating index system of environmental pollution third-party governance, which includes talents, technology, financing, industry isomorphism.

Firstly, from the perspective of the average wages of employees in the environmental service industry in Yangtze River Delta, there is a big difference between the monthly per capita wage level and the annual per capita wage level of the environmental protection industry in the three provinces and one municipality, especially the average wage levels of the environmental service industry employees in Shanghai municipality and Anhui province vary widely (Figure 11). In 2017, the monthly salary of employees in the environmental governance service industry in Shanghai municipality was 12,208 yuan, almost twice the average monthly salary of the industry in Anhui province (Figure 12); At the same time, this paper adopts the labor market openness represented by the difference between the annual average wage of employees in environmental service industry and the regional average annual wages. The greater the difference, the greater the openness. Then, the labor market for environmental pollution third-party governance in Shanghai municipality is much more open than in the other three provinces, and the labor market for environmental pollution third-party governance in Anhui province is less open (Figure 13).

Table 2. Market integrated index system of environmental pollution third-party governance in Yangtze River Delta

\begin{tabular}{|c|c|c|c|}
\hline Index & Sub-indicator & Indicator description & Indicator direction \\
\hline \multirow{4}{*}{$\begin{array}{l}\text { Market } \\
\text { uniformity } \\
\text { of the } \\
\text { environmental } \\
\text { pollution } \\
\text { third-party } \\
\text { governance }\end{array}$} & $\begin{array}{l}\text { Openness of the labor market in the } \\
\text { environmental service industry }\end{array}$ & $\begin{array}{l}\text { Replacement of the difference between the average annual } \\
\text { salary of environmental service personnel and the average } \\
\text { annual salary of regional employees }\end{array}$ & Positive \\
\hline & Environmental Technology Market & $\begin{array}{l}\text { Technology market turnover per capita of environmental } \\
\text { scientific research personnel }\end{array}$ & Positive \\
\hline & $\begin{array}{l}\text { Environmental service industry investment } \\
\text { and financing capabilities }\end{array}$ & $\begin{array}{l}\text { Comparison of the completed amount of industrial pollution } \\
\text { control investment }\end{array}$ & Positive \\
\hline & $\begin{array}{l}\text { Isomorphism of environmental service } \\
\text { industry }\end{array}$ & Structural coefficient of environmental service industry & Negative \\
\hline
\end{tabular}

Source: According to the "Exploration of Indicators for the Evaluation of the Integration of the Yangtze River Delta and New Discovery", "Nanjing Social Science", 2017, the seventh edition of the market integration indicators of the Yangtze River Delta was revised. 


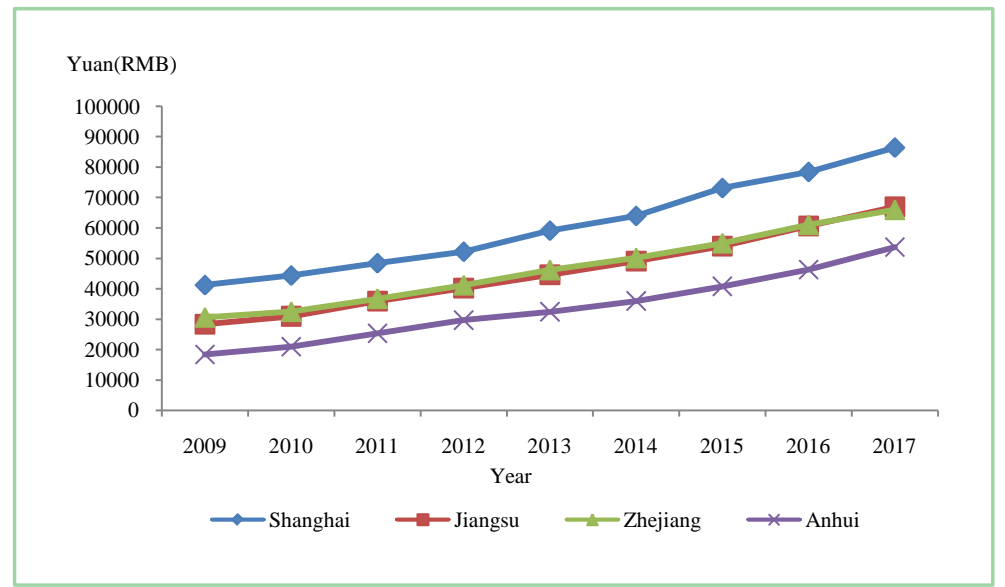

Figure 11. Annual per capita wage level of water conservancy and environmental service industries in three provinces and one municipality in Yangtze River Delta. (Data source: National data http://data.stats.gov.cn/).

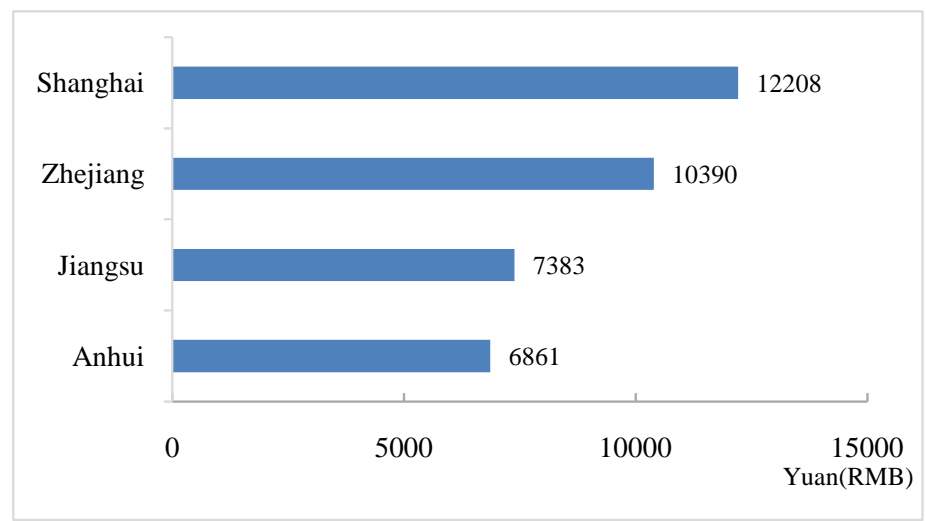

Figure 12. The average monthly wages of the environmental protection industry in three provinces and one municipality in Yangtze River Delta in 2017. (Data source: Environmental Protection Industry Payment Report (2017)).

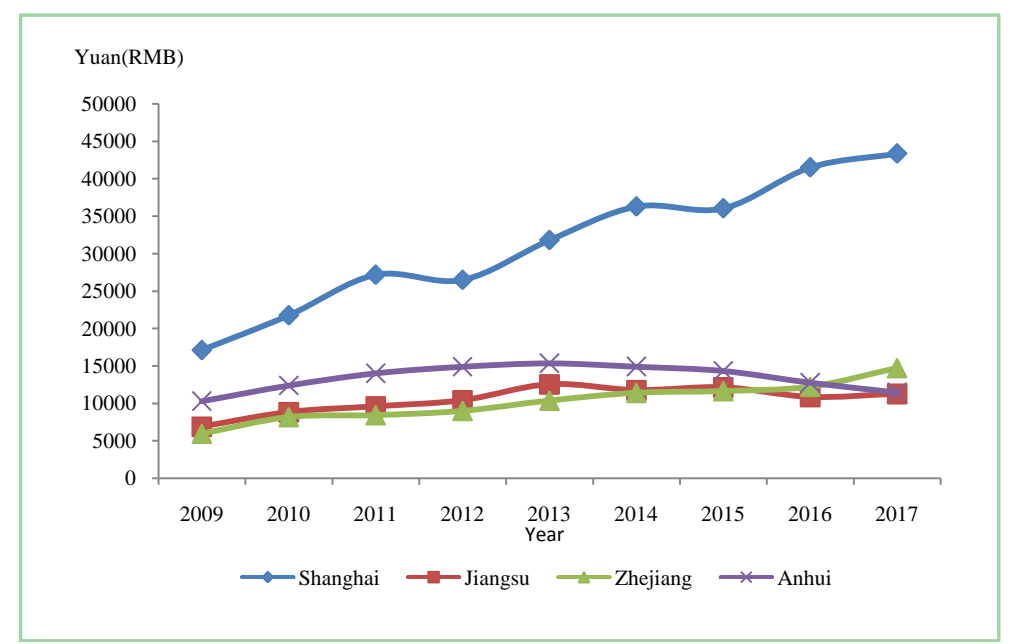

Figure 13. Comparison of labor market openness of environmental service industry in three provinces and one municipality in Yangtze River Delta. (Data source: National data http://data.stats.gov.cn/). 
Secondly, from the perspective of the turnover of the scientific research technology market, most of the key technologies in the environmental field in China are currently in the small-scale trial stage (Figure 14). In 2017, the technology market turnover per capita of scientific research personnel in the Yangtze River Delta was 290,000 yuan (RMB)/person, which was lower than the national level of 320,000 yuan (RMB)/person. Moreover, the technology market turnover per capita of scientific research personnel in Shanghai municipality and Jiangsu province were higher than the average level of the Yangtze River Delta and the national level. The level of annual scientific and technological innovation capability is lower than the average level of the Yangtze River Delta and the national level (Figure 15). Moreover, the employees of the environmental pollution third-party governance industry are characterized by a high proportion of highly educated and senior technical titles, and a large demand for R\&D, management and engineering technical personnel. Due to the high degree of technicality and specialization, the dependence on high-level talents is high (China Environmental Protection Industry Association, 2018). According to the Salary Report of Environmental Protection Industry (2017), environmental protection practitioners in three provinces and one municipality of Yangtze River Delta account for 30\% of China. The technological innovation potential of Yangtze River Delta relying on talents is huge, but it is urgent to promote the industrial transformation of environmental protection technology achievements. Innovative environmental governance technologies and standards are difficult to be recognized among locals in time, resulting in a lower overall level of environmental technology innovation and application in Yangtze River Delta region.

Thirdly, water pollution governance, air pollution governance and solid waste disposal are the key investment areas concerned by environmental pollution third-party governance market in Yangtze River Delta at present. From the perspective of investment in industrial pollution governance in Yangtze River Delta, the overall trend is rising (Figure 16), but investment of environmental pollution governance projects in Yangtze River Delta decreased by 33.3\% in 2017 compared with 2016. The amount of completed investment in environmental pollution governance in Jiangsu province, Zhejiang province and Anhui province decreased by a large margin, respectively down $40 \%, 38.7 \%$, and $37.7 \%$, and the investment in environmental pollution governance in Shanghai municipality decreased by $13.7 \%$.

Analyzing the macro factors, because the environmental protection industry entered difficult period in 2018, many enterprises of environmental pollution third-party governance in Yangtze River Delta suffered heavy losses by financial deleveraging, the PPP clear inventory, strong regulation etc. Under the action of multiple factors, environmental pollution third-party industry has not yet out of the financing bottleneck until now, and triggering a regional reshuffle in Yangtze River Delta.

Fourthly, this paper uses the industrial structure similarity coefficient $S_{i j}$ pro- 
posed by the International Industrial Research Center of the United Nations Industrial Development Organization (UNIDO) to measure the industry isomorphism of environmental pollution third-party governance service market in Yangtze River Delta. The industrial structure coefficient $S_{i j}$ among the whole third-party governance service market, or between two local markets is low (Figure 17), which shows that environment pollution third-party governance service industry in Yangtze River Delta has a low degree of isomorphism, and the development of differentiation is remarkable. But the similarity of environmental pollution third-party governance service market between in Shanghai municipality and Anhui province is relatively high, indicating that Anhui province has undertaken Shanghai municipality's environmental service industry to a certain extent.

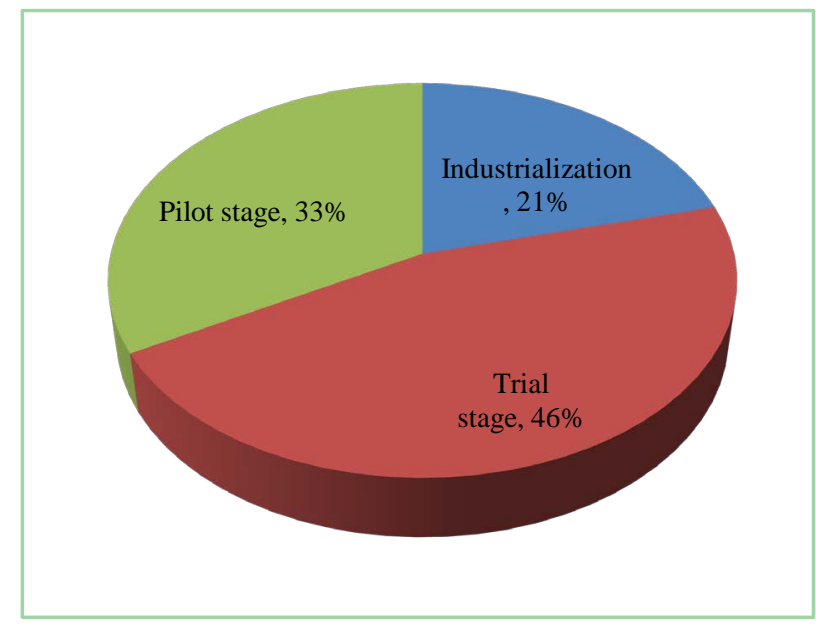

Figure 14. The level of key industrialization stages of environmental technology field in China, 2018. (Data Source: Environmental Technology Forecast 2018).

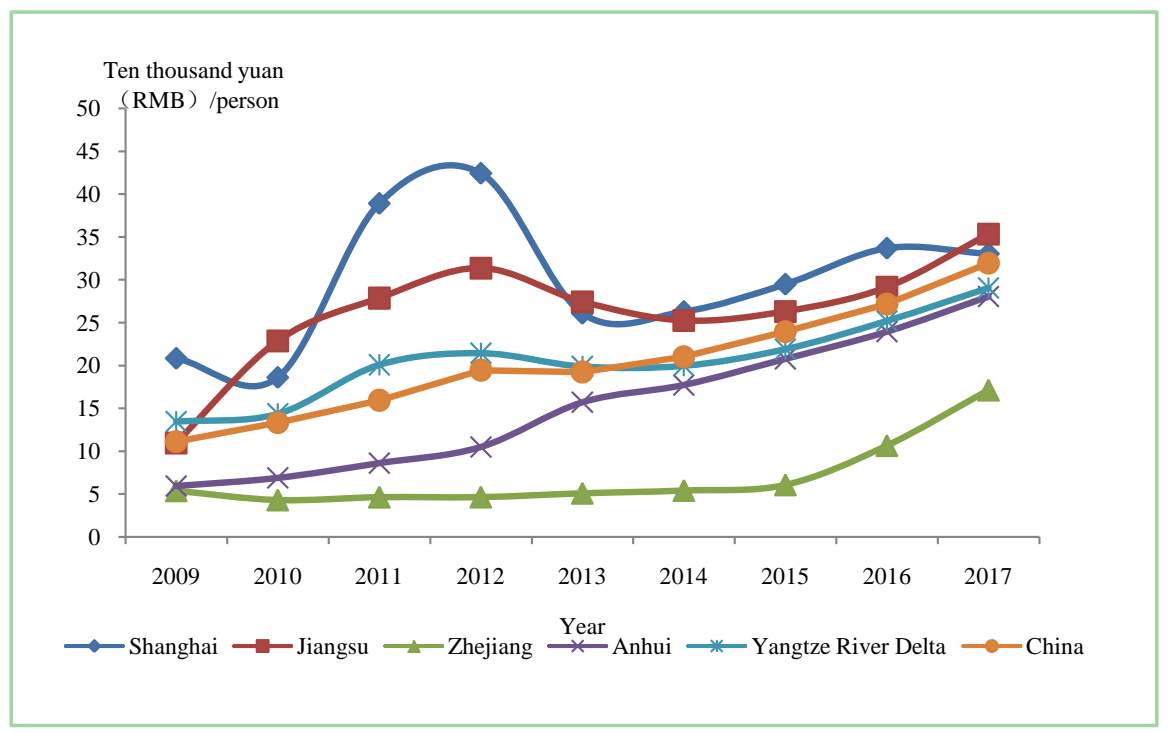

Figure 15. Comparison of per capita market turnover of scientific research personnel of Yangtze River Delta and China. (Data source: National data http://data.stats.gov.cn/). 


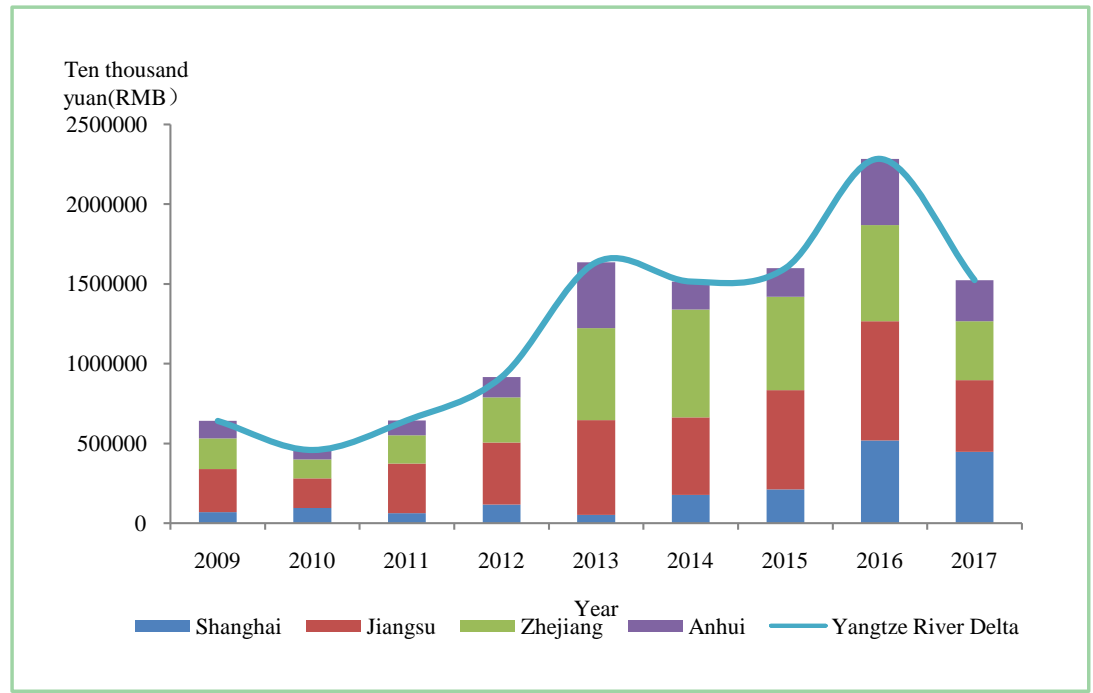

Figure 16. Changes in the amount of investment completed in industrial pollution governance of three provinces and one municipality in Yangtze River Delta in the past 10 years. (Data source: National data http://data.stats.gov.cn/).

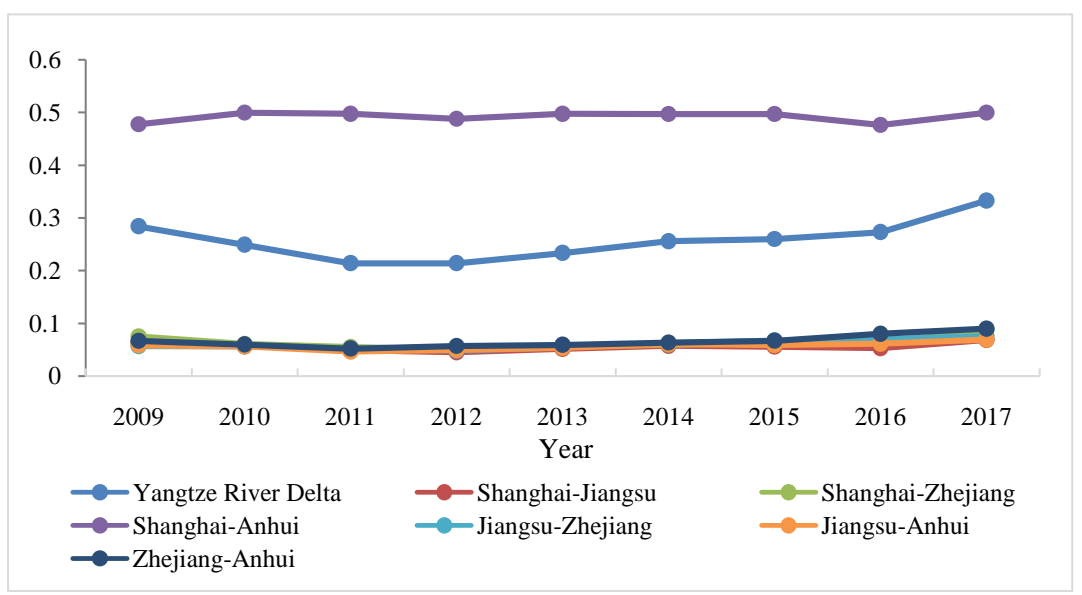

Figure 17. Comparison of the degree of isomorphism of water conservancy and environmental service industries among three provinces and one municipality of Yangtze River Delta. (Data source: National data http://data.stats.gov.cn/).

To sum up, environmental pollution third-party governance market in Yangtze River Delta at present is in an orderly opening stage, but the isomorphism of the environmental protection industry in each local of the region is more obvious, and there are still three problems in the supply side of environmental governance services:

1) The labor market of environmental governance services in most localities of Yangtze River Delta is less open, resulting in poor mobility of human resources for environmental governance services;

2) The innovation capability of environmental scientific research and technology in Yangtze River Delta needs to be improved and the environmental innovation and standards of technological innovation are not widely recognized in different administrative locals, making it difficult to promote new technologies 
in the region;

3) The finance for environmental pollution third-party governance industry is difficult and expensive. Financial institutions generally suspend loans of Public-Private-Partnership (PPP) projects for ecological and environmental protection, greatly reducing the "non-standard" financing activities. The approval cycle of some banks' credit approval has become significantly longer, and the preconditions for the financing enterprises of environmental pollution third-party governance enterprise, especially private environmental protection companies, have become harsher. The financing cost of some projects is as high as $11 \%$, which is close to or exceeds the normal profit level of the environmental protection industry.

\subsection{The Deep Facts of Influencing Factors for Integrating Environmental Pollution Third-Party Governance Market in Yangtze River Delta}

Based on the analysis of the industrial economics SCP model, the deep-seated reasons behind the integrated development of the environmental pollution third-party governance market in the Yangtze River Delta have found that the regionally environmental technical service standards are not uniform, there is no guarantee system to regulate regional market behavior, the market is single, and the regional market exists obviously administrative divisions. These factors have influenced the construction of an integrated system for environmental pollution third-party governance in Yangtze River Delta.

\subsubsection{The Environmental Technology Evaluation Standard and the Guarantee System Are Not Incomplete}

At present, the market of environmental pollution third-party governance in Yangtze River Delta is underdeveloped and imperfect, and a market conducive to fair competition by various entities has not yet been established. The primary reason is that the local standards for environmental technology involved in environmental pollution third-party governance are inconsistent, resulting in the technology innovation of environmental pollution third-party governance in Yangtze River Delta deprecated due to the mismatch between the emission standards for pollution governance and the local environmental quality improvement needs. However, in some places, there is a lack of in-depth systematic research on the formulation of standards, and even individual standards are copied from foreign standards, which does not fully meet the requirements of actual environmental quality improvement in the region, and objectively restricts the development of regionally environmental pollution third-party governance industries. At the same time, the intellectual property protection system for environmental technology services is flawed. Some small and micro enterprises often imitate the new environmental pollution governance technology to form low-price competition between different local markets, disrupting the order of the environmental pollution third-party governance market in Yangtze River 
Delta.

\subsubsection{Single Market Supply Body and Limited Financing Channels}

Environmental pollution third-party governance market in Yangtze River Delta is also relatively single in supply. About $70 \%$ enterprises are small and micro-scale environmental technology companies, environmental consulting service companies, and pollution governance facility operation companies. Their financing capabilities and advancement capabilities are limited. When there are major changes, or sudden public events (such as the global COVID-19 pandemic) cause the project to stagnate, it is difficult to bear the high financing costs and advancement costs, thus causing uncertainty to the sustainability of environmental pollution third-party governance projects. In addition, the projects of environmental pollution third-party governance in Yangtze River Delta are mainly indirect financing represented by banks and credit loans, also including facility (equipment) leasing models, fiscal and bank-style "environmental loans", and environmental PPP project asset securities, syndicated loans, and other financing service model innovations. However, without the guarantee from the main body of the insurance market, it is difficult for small and micro enterprises of environmental pollution third-party governance to obtain these innovative financing.

\subsubsection{Insufficient Internal Momentum in the Market, There Are Administrative Barriers}

Due to the imperfection of environmental protection technology standards and corresponding guarantee systems, and limited financing, environmental pollution third-party governance enterprises in Yangtze River Delta often lack the enthusiasm for environmental technology innovation, and are not sustainable for the application of advanced environmental technologies and equipment. The performance of the overall solution for environmental governance is relatively uncertain, which has led to the low enthusiasm for the model of environmental pollution third-party governance by the pollutants in Yangtze River Delta, and exacerbated the high financing costs. In addition, due to the local administrative division in Yangtze River Delta, environmental protection law enforcement and supervision in some places lack linkage, and the standard system of environmental service market transactions lacks mutual recognition and interoperability. Many enterprises of environmental pollution third-party governance have difficulty in entering projects and the transaction costs are high, resulting in the business environment of environmental pollution third-party governance industry in Yangtze River Delta is bad.

\section{The Construction Paths for Integrated Market of Environmental Pollution Third-Party Governance}

In view of the roots of factors affecting the market integration of environmental pollution third-party governance in Yangtze River Delta, this paper believes that the market of environmental pollution third-party governance in Yangtze River 
Delta needs to focus on three aspects of constructing market integration those are talent, technology, and capital. According to the SCP model of industrial economics, the key influencing factors in the integrated market system of environmental pollution third-party governance are environmental governance service standards, regional environmental cooperation governance mechanism, and regional environmental law enforcement supervision and reform. Those three factors are affecting regional market behavior.

\subsection{Establishing the Mechanism for Mutual Recognition of Pollution Compliance Emissions and Technical Standards in Yangtze River Delta}

In the governance process of water environment and atmospheric environment, the emission standards after pollution governed have always been the focus of attention between polluting enterprises and third-party governance enterprises. In the process of tracking specific projects in this article, firstly, it is found that there are differences between the national to local, local to local emission compliance standards. Third-party governance companies are more governed by the local emission compliance standards in the project implementation area, so that although the effect of third-party governance has reached the effect of the contract target, it still does not meet the national emission requirements. Then, when environmental service enterprises in Yangtze River Delta implement the model of environmental pollution third-party governance, they need to update the national and regional pollution discharge standards in a timely manner, and determine the project contract targets with higher compliance discharge standards. Secondly, due to the imperfect guarantee system, the environmental governance technology level and market value of third-party governance model are often not recognized by polluting enterprises in other locals of this region, which forces some small and micro third-party governance enterprises to participate in low-price competition to obtain projects, and disrupts the market competition order of third-party governance service, and cannot guarantee that low-cost projects have sustainable financial support. Therefore, on the basis of strengthening the assessment and identification of local environmental technology standards, the local environmental protection departments in Yangtze River Delta need to establish a mutual recognition mechanism of environmental technology standards with other local environmental protection departments, so as to form a unified environment technical standards and their value identification guide on the market of environmental pollution third-party governance in Yangtze River Delta, guiding benign price fluctuations in regionally environmental service market.

\subsection{Exploring the Multi-Agent Cooperative Governance Mechanism for Regional Environmental Pollution Third-Party Governance}

The main market players engaged in the market of environmental pollution 
third-party governance in Yangtze River Delta are small and medium-sized micro-pollution enterprises. Some of these enterprises have been developed from environmental technology service companies, and their capabilities in financing and business negotiation are relatively weak. A part of them have developed from companies of polluting equipment operation and management service, and are also relatively weak in financing, technology research and development, emergency management and other capabilities. However, the current environmental pollution problems are more and more comprehensive and sudden, and the governance period is longer, which require the participation of different market players to solve. Therefore, the main bodies of market demand for environmental pollution third-party governance should conduct diversified exploration of service providers. For each pollution governance project, it is necessary to cooperate with environmental negotiation service companies with business negotiation capabilities and companies with long-term operational management service experience, as well as to introduce environmental pollution third-party governance project guarantee entities and corresponding insurance entities to upgrade the financing capacity of the third-party governance body, and also to introduce an independent evaluation body to evaluate the performance of each pollution governance service project, and form a multi-agent cooperative governance mechanism to continuously improve the sustainability of environmental pollution third-party governance projects.

\subsection{Building Unified Regional Environmental Supervision and Law Enforcement Procedures in Yangtze River Delta}

At the initial and post-assessment of the project of environmental pollution third-party governance, the third-party governance enterprise needs to compare the objects of the environmental pollution third-party governance and the surrounding eco-environment quality with the indicators of local pollution compliance emissions, so that the project's performance of the contract subject and the implementation of the project includes environmental, economic and social aspects. However, due to the mobility of natural resources carried by these environments, if there is no uniform pollution-emission standard and corresponding regulatory enforcement rules in Yangtze River Delta region, cross-border environmental problems for the air and water will occur. And the resulting cross-border blame has brought "tragedy in the commons" to the public goods of high-quality ecological environment in the region. Therefore, before the environmental protection departments of Yangtze River Delta jointly formulate unified environmental pollution compliance emission standards, local environmental law enforcement departments must first jointly formulate unified regional environmental supervision and enforcement procedures to eliminate joint supervision and enforcement problems hindered by administrative divisions, so that to make the pollutant discharge enterprises clear the same consequences of non-compliance of pollutant discharge, stealing and leaking, which also enable third-party governance enterprises to have goals, confidence, and determination 
to implement environmental pollution third-party governance projects, thereby improving the supply and demand of environmental pollution governance and promoting cross-border environmental pollution third-party governance projects in Yangtze River Delta.

\section{Conclusion and Suggestion}

\subsection{Research Conclusion}

Through the analysis of the characteristics of Yangtze River Delta environmental governance market and the factors influencing integration, this paper concludes the construction paths for building an integrated market for environmental pollution third-party governance in Yangtze River Delta, which are: 1) Establishing the mechanism for regional mutual recognition of pollution compliance emissions and technical standards; 2) Exploring the multi-agent cooperative governance mechanism for regional environmental pollution third-party governance; 3) Building regional unified regional environmental supervision and law enforcement procedures, in order to effectively improve the scale effect of the environmental pollution third-party governance in Yangtze River Delta, and promote the rapid transfer of environmental technology in the region.

\subsection{Suggestions}

In order to further improve the market performance of the environmental pollution third-party governance service in Yangtze River Delta, this article suggests that three provinces and one municipality in Yangtze River Delta need to use the permanent organization of the "Yangtze River Delta Regional Cooperation Office" that has been established in 2018 to play a role in the ecological environment of this cross-administrative permanent organization at the regional level, whose governance coordination and negotiation functions can assist in building a standard library of market environmental standards for environmental pollution third-party governance in Yangtze River Delta, and build a unified platform that promotes regional market body trading cooperation and supervises regionally environmental pollution third-party governance performance.

\subsubsection{Establishing Standard Library of Environmental Technology in Yangtze River Delta Based on the Green Technology Bank}

Cooperate with the Yangtze River Delta integrated national development strategy, the local governments of three provinces and one municipality in Yangtze River Delta need to increase the demonstration and transformation of environmental scientific and technological achievements respectively, and increase technical support for the realization of green development in Yangtze River Delta. The advanced green environmental technologies determined by the three provinces and one municipality will be re-identified by the Green Technology Bank, and the environmental governance technologies applicable to the Yangtze River Delta region will be summarized to form a key regionally environmental technology standard library and become part of the Green Technology Bank da- 
tabase. The Green Technology Bank will determine a unified minimum market price standard for environmental governance technologies in Yangtze River Delta, guide market players to bid reasonable price, and promote the transfer of green technologies.

\subsubsection{Cultivating New Third-Party Governance Innovation Entities and Their Trading Platforms}

Each local market of three provinces and one municipality in the Yangtze River Delta should fully utilize the market mechanism based on existing environmental consulting services, environmental technology services, pollution facility operation services, waste resource recycling and disposal services, environmental trade and financial services. Through institutional mechanisms innovations, such as the horizontal ecological compensation mechanism based on the trading of environmental elements such as water rights, carbon emission rights, and pollution emission rights, and the new sharing mechanism of environmental risks in Yangtze River Delta, innovation entities such as society and NGOs will be cultivated. Working with the development and reform commissions, economic and information commissions and other government departments in Yangtze River Delta will build a trading platform for environmental pollution third-party governance projects to promote the market development of environmental pollution third-party governance in the Yangtze River Delta considering regional cross-border typical environmental issues.

\subsubsection{Building a Unified Platform of Performance Supervision for Regionally Environmental Pollution Third-Party Governance}

Although the central government in China has issued technical guidelines for self-monitoring of pollutant discharge enterprises in various industries such as electroplating, agricultural and sideline food processing industry, pesticide manufacturing industry, flat glass industry, and non-ferrous metal industry in 2018, the ecological and environmental protection departments of three provinces and municipality in Yangtze River Delta have set up real-time monitoring system of air and water environment quality, but which does not mean that the local government can constantly monitor the pollution of all polluting enterprises in the region. At the same time, according to the catalogue for the Administration of Classification of Discharge Permits for Stationary Pollution Sources 2017 (Ministry Order No. 45), the Ministry of Ecology and Environment requires agricultural and sideline food processing industry, wine, beverage and refined tea manufacturing, furniture manufacturing, water production and supply Nineteen industries, including the industries obtained national emission permits at the end of 2019 and required companies in these industries to meet industry emission standards. For this reason, most of these enterprises introduced projects of environmental pollution third-party governance to meet their emission standards. However, in the actual on-site monitoring of local governments, it is often found that enterprises in some administrative jurisdictions and non-administrative jurisdictions have excessive emissions, resulting in damage 
to the air, water, and soil ecological environment around the enterprise, especially in transboundary areas. Therefore, each local eco-environmental protection department not only needs to monitor the quality of the ecological environment in the administrative area in real time, but also needs to jointly supervise the performance of the third-party governance project on environmental pollution and form a big data platform to collect performance monitoring data for environmental pollution third-party governance in Yangtze River Delta, so as to jointly prevent possible regionally environmental risks in the Yangtze River Delta.

However, due to the difficulty in the availability of the latest data, the environmental governance service industry data used in this article is until 2018, so that the results of the analysis have a certain lag; at the same time, there is no in-depth study of third-party governance services in different environmental field. Therefore, in the future research, case analysis and empirical analysis will be used as research methods to carry out integrated mechanism research and the latest research on environmental pollution third-party governance service market in Yangtze River Delta. Research on the integration mechanism of the service market has explored policy recommendations for regional governments to improve the overall performance of regional environmental services.

\section{Acknowledgements}

For authors integrated in Shanghai Academy of Social Sciences (SASS), the research was financed by Research Fund of SASS, under bidding project "Research on Modernization Level of Environmental Pollution Governance and Market Integration Mechanism in Yangtze River Delta", and supported by Planning Funds of Shanghai Social Science, under the general topics project 2018BJB007.

\section{Conflicts of Interest}

The authors declare no conflicts of interest regarding the publication of this paper.

\section{References}

Chen, T. (2017). Third-Party Governance: Theoretical Paradigm and Practical Logic. Political Science Research, No. 1, 90-98.

Dong, Z. F., Dong, W., Tian, S. Y., Cheng, C. Y., \& Zang, X. (2016). Roadmap for the Mechanism Reform of Environmental Pollution Third-Party Governance in China. Chinese Environmental Management, 8, 52-59.

$\mathrm{Hu}$, B. (2019). High-Quality Integration in Yangtze River Delta, China: Background, Challenges, and Connotation. Science Development, No. 4, 67-76.

Huang, H., \& Ding, H. P. (2019). Research on Environmental Pollution Third-Party Governance of Coal-Fired Power Plants. Resource Science, 41, 326-337.

Huang, X. J., Luo, J. H., \& Fan, P. P. (2017). Research on the Marketization of Environmental Governance. Environmental Protection, 45, 48-52.

Li, C. Y., \& Mao, S. L. (2018). Theory on the Structural Obstacles to Environmental Pol- 
lution Third-Party Governance in China. Environmental Protection, 46, 46-50.

Li, S. Q., \& Zhu, P. F. (2017). Exploration of Indicators for the Integration Evaluation of Yangtze River Delta and Its New Discoveries. Nanjing Social Sciences, No. 7, 33-40.

Liu, C. (2015). Regulation, Interaction, and Environmental Pollution Third-Party Governance. Chinese Population Resources and Environment, 25, 96-104.

Liu, C. X. (2018). Legal Responsibility Basis and Reasonable Boundary of Environmental Pollution Third-Party Governance. Jurisprudence, No. 6, 182-192.

Lu, Z. K., \& Lin, R. Q. (2019). Environmental Pollution Third-Party Governance in River Basin: Contractual Relationship and Institutional Logic. Journal of Renmin University of China, 33, 150-157.

Luo, J. H. (2014). Development and Improvement of Environmental Pollution Third-Party Governance. Environmental Protection, 42, 16-19.

Pei, Y. Y., Luo, H., Xue, J., Xie, X. S., \& Shi, D. D. (2018). Analysis of China's Environmental Service Industry Based on SCP Paradigm. Chinese Environmental Management, 10, 89-93.

Ren, W. T., \& Wang, Y. (2014). Experience, and Inspiration of Environmental Pollution Third-Party Governance in Japan. Environmental Protection, 42, 34-38.

Song, T. (2014). Using the Market Mechanism to Promote the Integration of Environmental Protection in Beijing Province, Tianjin Province, and Hebei Province, China. http://www.h2o-china.com/news/212566.html

Sun, B. W., \& Chen, Z. Q. (2019). Market-Integrated Industrial Pollution Emission Mechanism: An Example of the Yangtze River Economic Belt. Chinese Environmental Science, 39, 868-878.

Wan, Z. H. (2017). A Comparative Study of Environmental Pollution Governance Policies in China and Australia-Taking Third-Party Governance as an Example. Safety and Environmental Engineering, 24, 29-33.

Xie, H. Y. (2014). Practices and Suggestions on Environmental Pollution Third-Party Governance. Macroeconomic Management, No. 12, 61-62.

Xue, J., Zhou, J. B., Cao, B., Pei, Y. Y., Luo, H., \& Li, B. J. (2016). Economic Performance Evaluation of Key Development Areas of China's Environmental Protection Industry. Environmental Pollution \& Prevention, 38, 98-105.

Zeng, Q. H., Zong, G., \& Han, J. L. (2018). Choice of Urban Environmental Pollution Governance Mode-Analysis of the Practicality of Third-Party Pollution Control Mode. Price Theory and Practice, No. 6, 142-145.

Zhang, F. (2020). Research on Social Third-Party Governance of Environmental Pollution. Journal of Huazhong Agricultural University (Social Science Edition) No. 1, 118-123.

Zhou, W. Q. (2017). Formation Logic and Dilemma Breakthrough of Environmental Pollution Third-Party Governance in China. Modern Economic Research, No. 1, 33-37. 